\title{
Faculdades da alma e suas implicações para a educação: saberes divulgados no século XIX
}

\author{
Raquel Martins de Assis \\ Juliana de Souza Martins \\ Universidade Federal de Minas Gerais
}

\section{Resumo}

Este artigo descreve resultados de uma pesquisa que buscou investigar como o tema das faculdades da alma e de suas implicações no desenvolvimento humano e na educação da pessoa foi divulgado, ao final do século XIX, pela imprensa periódica. Esperando contribuir para a história da psicologia e da educação, o artigo apresenta a análise de escritos sobre educação moral e educação estética de uma Secção Scientifica ou Pedagógica assinada por José Miguel de Siqueira e publicada no jornal $O$ Baependyano (1877-1889). Inicialmente, são feitas breves descrições do periódico e de sua posição na conjuntura da época, bem como do lugar em que foi publicado. Em seguida, tratamos da definição de pedagogia apresentada pelo jornal, levando em consideração as apropriações de autores estrangeiros comumente presentes no campo da educação. A pedagogia considerada moderna é defınida em tais escritos como a expansão e o desenvolvimento das forças animais, racionais e morais do ser humano; sua finalidade seria a formação do homem social pronto para o trabalho e para o serviço da sociedade e do Estado. Partindo dessa discussão, abordamos as concepções de educação espontânea, educação regular e instrução contidas no periódico. A educação é entendida como a unidade entre cultura e instrução, sendo a cultura a principal responsável pelo direcionamento das faculdades da alma e pela formação moral; a instrução, por sua vez, é tomada como aquisição de conhecimentos, mas também desempenha um papel importante na formação de hábitos e costumes.

\section{Palavras-chave}

Educação - História da psicologia - Faculdades da alma - Século XIX

- Cultura impressa.

\begin{abstract}
Correspondência:
Raquel Martins de Assis

raamart@yahoo.com.br
\end{abstract}

* Apoio Fapemig. 


\title{
Faculties of the soul and their implications for education: knowledges circulated in the 19th century
}

Raquel Martins de Assis

Juliana de Souza Martins

Federal University of Minas Gerais

\begin{abstract}
The article describes the results of a research that investigated how the theme of the faculties of the soul and of their implications for human development and for the education of a person was made available in the late 19th century by the circulating press. In an attempt to contribute to the history of psychology and education, the article presents the analysis of writings on moral education and aesthetic education that appeared on a scientific or pedagogical section signed by José Miguel de Siqueira and published in the 0 Baependyano (1877-1889) periodical. Initially, brief descriptions of the periodical and of its position within the context of the time are made, as well as of the place at which it was published. Next, we deal with the definition of pedagogy presented by the periodical, taking into account the appropriations of foreign authors commonly present in the field of education. Pedagogy, regarded as modern, is defined in those writings as the expansion and development of the animal, rational and moral strengths of the human being; its purpose would be the formation of the social man ready for work and for the service of society and of the State. Based on this discussion, we investigate the conceptions of spontaneous education, regular education, and instruction contained in the periodical. Education is understood as the unity of culture and instruction, with the former being the chief responsible for directing the faculties of the soul and for moral formation; instruction, by its turn, is seen as the acquisition of knowledge, but also plays an important role in the formation of habits and customs.
\end{abstract}

\section{Keywords}

Education - History of psychology - Faculties of the soul - 19th century

- Written culture.

Contact:

Raquel Martins de Assis

raamart@yahoo.com.br

* Supported by Fapemig. 
Este artigo apresenta uma análise da relação entre saberes sobre psicologia e educação presentes no jornal mineiro $O$ Baependyano: folha scientifica, litteraria e noticiosa (18771889), buscando entender os conceitos de natureza humana que fundamentam os discursos sobre educação do século XIX. Partindo do pressuposto de que é possível compreender a psicologia daquela época como sistematização de saberes sobre as faculdades da alma, a pesquisa teve como objetivo específico investigar tais saberes e suas implicações no desenvolvimento e na educação da pessoa, tal como foi divulgado no impresso mineiro. A investigação foi realizada como parte da pesquisa intitulada História da psicologia da educação em Minas Gerais: relações entre saberes sobre psicologia e educação em jornais mineiros do século XIX (2008-2010) e apresenta-se como uma continuidade dos estudos Fontes para a difusão das idéias psicológicas em Minas Gerais entre 1830 e 1930, de Denise Maria Nepomuceno e Regina Helena Campos (2004), e Psicologia filosófica em compêndios do século XIX: contribuições para a história da psicologia da educação em Minas Gerais, de Raquel Martins de Assis e Flávio de Ligório Silva (2006).

A cultura impressa periódica do século XIX tem sido reconhecida como importante objeto e também como rica fonte de pesquisa sobre o Brasil, pois nela é possível encontrar projetos políticos, visões de mundo representativas de diversos setores da sociedade e relatos do cotidiano, além da produção e da difusão de ideias educacionais e saberes científicos (LUSTOSA, 2003; NEVES; MOREL; FERREIRA, 2006; CAMISASCA; VENÂNCIO, 2007; ARAÚJO, 2008; JINZENJI, 2010). De fato, os próprios homens da época consideravam que a imprensa periódica era um importante instrumento de circulação e divulgação de ideias e preceitos, bem como um poderoso agente educacional (COSTA FILHO, 1955; BAHIA, 1972; RODRIGUES, 1986; PALLARESBURKE, 1996; OLIVEIRA, 1997; SCHWARCZ, 1998; NEVES, 1999).
Os jornais publicados no Brasil, fundamentando-se em princípios iluministas, buscavam contribuir para um projeto civilizatório por meio da divulgação de preceitos e valores capazes de educar, instruir e ilustrar os leitores (JINZENJI, 2010). Esses impressos veiculavam ideias de uma elite intelectual e política que se apresentava como portadora dos signos da civilidade. A imprensa funcionava como instrumento de ação educacional ao permitir que a população tivesse acesso aos ideais capazes de inculcar uma cultura e determinados hábitos nas pessoas consideradas incivilizadas (FARIA FILHO et al., 2008).

Embora os jornais de divulgação científica tenham sido tomados como objetos de estudo e amplamente utilizados como fontes para a pesquisa em história da psicologia, outros tipos de periódicos ainda são pouco explorados. Entretanto, a análise de periódicos do século XIX pode ser bastante interessante para a história da psicologia, devido à importância da cultura impressa no período, à dimensão educativa desses impressos e ao fato de que eles comumente divulgavam as teorias científicas, literárias e filosóficas de sua época.

Nos escritos do século XIX, a palavra psicologia possui diversos sentidos (ASSIS, et al., 2009). Porém, é comum que ela apareça relacionada ao tema das faculdades da alma, como demonstra a passagem a seguir:

A educação física ou do corpo é a que procura formar homens robustos e sadios, tornando-os aptos para os diversos misteres da vida laboriosa. A educação intelectual é a que trata do desenvolvimento das faculdades da alma, com que Deus dotou as creaturas. 0 tratado dos phenomenos d'essas faculdades denomina-se psychologia. A educação moral é a que tem por objetivo encaminhar o homem para o amor do bem. ${ }^{1}$

1 - Revista Escolar, Ouro Preto, n. 7, 1889, p. 3-4. 
De acordo com o que afirma a Revista Escolar de 1889, mesmo no final do século XIX, época em que a psicologia experimental praticada em laboratório já se constituía como um saber autônomo, a psicologia podia ser entendida como a parte da filosofia que estudava as faculdades da alma. 0 termo psychologia é assim utilizado em diversos compêndios e também em programas de cursos de instituições educacionais, como seminários, colégios, cursos de filosofia, faculdades de direito e de medicina (MASSIMI, 1989). Apesar de certo consenso sobre o campo de conhecimento ao qual se refere a psicologia, as matrizes teóricas que servem de suporte às sistematizações sobre as faculdades da alma são as mais diversas. Como exemplo, encontramos o ensino de psicologia no Seminário Episcopal de São Paulo:

Ainda no século XIX, o ensino de Psychologia fazia parte do programa de estudos Filosóficos do Seminário, como atestam os manuais de filosofia, franceses e brasileiros, presentes em sua biblioteca. De modo geral, junto com outras disciplinas, tais como a Antropologia, a Metafísica e a Teologia Moral, a Psicologia era considerada uma disciplina fundamental para a compreensão do homem como um todo, corpo e alma. A abordagem vigente ratificava idéias centrais da doutrina da alma de Santo Tomás de Aquino e aspectos do espiritualismo francês. Sem propor uma ruptura entre a Psicologia Filosófica, a Ontologia Tomista e a nova Psicologia Científica, discutia-se a noção de alma e suas faculdades, o sono e o sonho, a memória, a percepção, a inteligência, a consciência, a imaginação, a vontade e os afetos. (ASSIS; SILVA; PACHECO, 2011, p. 387)

Durante o século XIX, tal como discutido no excerto acima, os autores ligados ao ensino de psicologia, de modo geral, buscavam uma conciliação entre filosofia, metafísica e ciência, propondo como método não a experimentação em laboratório, mas a introspecção como experiência de observar a si mesmo. Especificamente em Minas Gerais, esse movimento de conciliação entre fé, filosofıa e ciência deu-se sob o bispado de D. Antônio Ferreira Viçoso, durante o qual se produziu a obra Esqueleto das faculdades e origem das idéias do espirito humano, obra mui útil para os moços que se applicão ao estudo de Philosophia (1847), de autoria de João Antônio dos Santos. Nesse pequeno compêndio produzido para o ensino de psicologia, encontramos o termo alma definido como "um ente dotado de força, capaz de agir impulsionado pela sua relação com os objetos" (ASSIS, 2009, p. 306), sendo as faculdades associadas aos movimentos ativos e passivos da alma e às ideias de força. Nesse sentido, as faculdades podem ser descritas como forças animais, racionais e morais cujo desenvolvimento pleno necessita de direção e cultivo. Tal direcionamento, por sua vez, caberia à educação.

Diante das explícitas relações entre psicologia, educação e faculdades da alma, surgiu a ideia de investigar os temas da educação e do desenvolvimento da pessoa a partir das discussões sobre as faculdades da alma inseridas nos jornais mineiros. Assim, a pesquisa intitulada História da psicologia da educação em Minas Gerais: relações entre saberes sobre psicologia e educação em jornais mineiros do século $X I X$, que serviu de ponto de partida para o presente artigo, buscava responder a questões como: que concepções de natureza humana e de educação circulavam nos jornais mineiros do século XIX?; de que modo as ideias sobre as faculdades da alma fundamentavam os conceitos de natureza humana e de educação divulgados por tais impressos, já que esse saber parece ter sido um interesse dos educadores da época?

Numa primeira etapa da pesquisa, foram catalogados 46 jornais do século XIX, entre 1823, ano em que se publica o primeiro jornal em Minas Gerais, e 1890, época em que se iniciam os primeiros momentos da República (ASSIS; MARTINS; VIEIRA, 2009). 0 primeiro 
critério para a realização desse recorte está relacionado à história dos impressos em Minas Gerais: a publicação de periódicos na província começa a partir de 1823, sendo possível constituir uma amostra apenas após esse período. A data final para o recorte temporal foi escolhida devido ao início da República, como já mencionado. Obviamente, periódicos publicados em datas mais próximas ao final do século já antecipam muitos dos temas, problemas e modos de entender a educação e a ciência que vão vigorar durante a República. Entretanto, finalizar o recorte no ano de 1890 permitiu tomar o período imperial como um aspecto de coesão da pesquisa. Assim, foi feita a catalogação de uma amostra de jornais de cada década do século XIX, de 1823 até 1890 , e, na medida do possível, foram escolhidos diferentes locais de publicação, de forma a atingir diversas regiões da província.

A partir do levantamento e da catalogação dessa amostra, foi possível perceber que os jornais mineiros traziam muitos dados sobre as faculdades da alma e sobre a educação como responsável por seu direcionamento. Tendo sido realizada essa primeira parte da pesquisa, entendemos que seria interessante, para os objetivos do estudo, analisar uma das fontes de forma mais aprofundada. Dentre os periódicos catalogados, escolhemos o jornal $O$ Baependyano (1877-1889), por ele conter uma Secção Scientifica ou Pedagógica, redigida por José Miguel de Siqueira, cujo objetivo era discutir a educação em diversos âmbitos. Tal seção tratava, entre outros aspectos, do tema das faculdades da alma e de seu direcionamento por meio da educação.

Esperando contribuir para a história da psicologia e da educação no Brasil, este artigo organiza-se da seguinte forma: inicialmente, descrevemos o jornal $O$ Baependyano e sua posição no contexto da época; em seguida, tratamos da moderna pedagogia divulgada pelo periódico e do desenvolvimento das forças animais e racionais do ser humano, levando em consideração as apropriações de autores estrangeiros comumente divulgados no campo da educação; a partir dessa discussão, abordamos as concepções de educação e instrução contidas no periódico.

\section{O jornal O Baependyano (1877- 1889) e sua Secção Scientífica ou Pedagógica}

O Baependyano surgiu em julho de 1877, sendo publicado semanalmente na cidade de Baependi, localizada ao sul de Minas Gerais e, na época, no município de Caxambu. 0 periódico circulou pela região até novembro de 1889; em seu oitavo ano de publicação, mais precisamente em abril de 1884, sua sede foi transferida para Caxambu. Assim como outros jornais da época, ele era composto por seções sobre literatura, ciências, pedagogia, religião e indústria. $A$ Secção Scientifica ou Pedagógica ocupava sempre a primeira ou segunda página do jornal, mas não estava presente em todos os números. 0 periódico também tratava de assuntos e notícias políticas, especialmente da Câmara Municipal de Baependi, divulgava diversas informações, como notícias sobre colégios para meninas e internatos, notas sobre publicação e venda de livros e jornais, propagandas comerciais e de serviços como advocacia e atendimento médico. Além disso, fazia homenagens às pessoas ilustres da época, trazia notas de falecimento e ainda contemplava alguns alforges, ou seja, reflexões sobre pensamentos e temas variados. Cada exemplar era composto por quatro páginas, sendo que a última destinava-se à propaganda de serviços prestados na cidade e ao anúncio de venda e fuga de escravos, como tradicionalmente se fazia nos jornais do século XIX.

Seu proprietário, Amaro Carlos Nogueira, homem de grande influência no cenário político, era membro do Partido Liberal e foi deputado provincial, jornalista, dono de escola e colunista do primeiro jornal de Baependi, intitulado Amor ao progresso (PELÚCIO, 1942). Mais tarde, Nogueira publicou O Baependyano, que, de acordo com Fábio Francisco de Almeida Castilho (2009), representava um grupo muito 
bem definido: lavradores e fazendeiros da região contrários ao abolicionismo, mas defensores de uma lenta emancipação dos escravos, a serem substituídos pela mão de obra imigrante. Assim, o grupo ligado a $O$ Baependyano e a Nogueira proclamava-se contra a escravidão, mas defendia que a abolição repentina traria graves consequências ao país, tal como afirma Castilho (2009):

Antes de tomar medida semelhante era necessário educar o trabalhador nacional, elemento vadio que deveria ser disciplinado e inserido no mercado de trabalho, enquanto a vadiação era tida como "infecção terrível" que deprimia e solapava a moral e o direito da sociedade. (p. 103)

Desse modo, assim como se ministra um remédio, era preciso educar o trabalhador nacional para a economia e para a política, incluindo os libertos e os indígenas. Aparece nesse cenário a defesa da imigração estrangeira como uma das alternativas diante da necessidade de uma transição da mão de obra escrava para a livre. Para tanto, $O$ Baependyano utilizou diversas estratégias: a edição de 15 de julho de 1877, por exemplo, informa que seus assinantes anuais ganhariam um exemplar do volume Brazil: colonização e emigração (s.d.), acompanhado da opinião da imprensa brasileira e estrangeira sobre o assunto.

A imigração, portanto, era um tema constante no jornal, sendo que em diversos exemplares do ano de 1879 foi publicado um estudo sobre a colonização no Sul de Minas. Após um pequeno trecho sobre a cidade de Baependi, porém, o autor narra o movimento de imigração no Paraná e a maneira como o trabalhador imigrante estrangeiro se inseria na região Sul do país. Em determinado momento, o estudo afirma: "a ferramenta agrária que ali se distribue ao colono consta de uma pá, uma enchada, um machado, uma picareta e uma foice" ${ }^{2}$. Logo na sequência

\footnotetext{
2- O Baependyano, n. 93, 23 abr. 1879, p. 1
}

desse texto, o periódico apresenta uma Secção Industrial, na qual se descrevem os arados e aparelhos acessórios para a agricultura, evidenciando uma possível intenção do jornal em propor uma imigração talvez calcada em princípios mais modernos.

Diante disso, os temas do periódico giram, na maior parte, em torno do tema do trabalho, especialmente do trabalho rural, sendo que praticamente todas as edições do jornal possuíam a parte denominada Secção Industrial. Geralmente, tal seção tratava de agricultura e de novos métodos e maquinários para a lavoura.

Inserindo-se em um espírito de modernidade, O Baependyano, além de exaltar máquinas e novidades para a agricultura, também apresenta uma concepção de trabalho como algo que engrandece a pessoa e a nação, e não como ação inferior destinada ao escravo (CASTILHO, 2009). Junto a essa concepção, o periódico traz a moderna pedagogia divulgada por Siqueira, claramente ligada aos saberes científicos da época. Também modernos são os anúncios sobre a moda parisiense, sobre coleções de ciência popularizada, sobre os periódicos norte-americanos e europeus, entre outros.

Apesar da clara posição política de Amaro Nogueira, principal redator do jornal, O Baependyano declarava-se como uma folha scientifica, litteraria e noticiosa responsável por levar ao povo as questões que lhe interessavam, sem, contudo, ferir a moral universal. Em seu edital, o jornal continha o seguinte escrito:

Na parte que nos é reservada, agitamos as questões que mais interessam o povo, sem despozar a causa de nenhum dos partidos existentes, e com o respeito devido aos princípios da moral universal e ás leis da nação. No editorial, excluindo as questões de vida privada, permittimos ampla liberdade d'enuciação do pensamento, desde que haja responsabilidade do auctor e a linguagem do escripto seja conveniente. ${ }^{3}$

\section{3- 0 Baependyano, 5 set. 1880, p. 1}


Além de informar a população, o periódico também apontava como missão "doutrinar o povo sobre o que lhe importa saber" e vangloriava-se por ser "um dos principais diretores de opinião na parte mais adiantada do império" ${ }^{4}$. Entre as questões que, segundo o periódico, interessavam ao povo, estavam as ideias sobre o trabalho e sua dignidade para a modernidade (CASTILHO, 2009), bem como sobre educação.

Na edição de 17 de abril de 1879, o autor de uma obra sobre a colonização brasileira dirige-se a Nogueira como uma pessoa que "tanto tem se dedicado ao ensino e educação do povo" 5 . Nesse mesmo número, a cidade de Baependi é descrita como portadora de "uma bem dirigida imprensa que, com solicitude e esmero, promove a educação do povo" .

Os textos de $O$ Baependyano que compõem as seções sobre educação são de autoria de José Miguel de Siqueira, sendo difícil definir se ele era um efetivo colaborador do jornal ou se apenas teve seus excertos nele publicados. Pelas informações obtidas ${ }^{7}$, Siqueira era tenente-coronel e intitulava-se lavrador e fazendeiro na região de Barbacena. Foi também deputado provincial no ano de 1877 e, ao que parece, fazia parte do grupo de lavradores e fazendeiros que se expressavam no periódico, liderados por Amaro Carlos Nogueira. É autor do livro Educação religiosa ${ }^{8}$ (1883) e teve seus escritos também publicados no jornal Vinte de Agosto: o Órgão do Partido Conservador (18851886), que circulava na cidade de Ouro Preto.

Inserido no espírito do periódico e também da época, os textos da Secção Scientífica ou Pedagógica tratavam a educação como instrumento privilegiado para a formação do homem social, ou seja, o ideal de ser huma-

4 - $O$ Baependyano, 5 set. 1880, p. 1.

5- O Baependyano, n. 91, 17 abr. 1879, p. 1.

6- lbid.

7- Uma dificuldade desta pesquisa foi encontrar dados precisos sobre José Miguel de Siqueira. Além das informações inseridas no texto, sabemos apenas que ele teve dois filhos matriculados no Colégio do Caraça.

$\mathbf{8}$ - Até o presente momento, ainda não foi localizado o livro escrito por José Miguel de Siqueira. no instruído, polido, trabalhador, civilizado e dotado de boas maneiras sociais.

A Secção, ao longo dos exemplares consultados, tratou de cinco grandes temas: educação moral, educação social, educação estética, educação doméstica e social e educação física. Nessas subseções, o autor descreve a importância da boa educação (principalmente no que diz respeito à leitura e à escolha dos livros) e da polidez para o desenvolvimento das virtudes sociais; aborda os deveres entre pais e filhos e a importância do casamento, da maternidade e da educação social e cristã; trata da faculdade da imaginação e da necessidade de instruir os homens não somente pela razão, mas também por meio da beleza das artes; e, por fim, discute a importância da educação do corpo para a conservação do espírito.

Partindo dessa descrição, vemos que a Secção Scientífica ou Pedagógica aponta para diversos temas comuns do século XIX, por exemplo, a polidez vista como virtude social, as questões de gênero, ideias sobre os livros, a leitura e suas práticas, entre outros. Entretanto, partindo da noção de apropriação de Michel de Certeau (1994), é interessante observar como esses temas característicos do século XIX aparecem tratados em um periódico cujo mote central é a formação do trabalhador brasileiro em um contexto de progressiva abolição da escravidão. Nesse sentido, também os saberes sobre as faculdades da alma divulgados pelo periódico, em suas relações com os discursos sobre a educação da pessoa, devem ser considerados a partir de tal contexto. Como afirmam Raquel Martins de Assis (2009), Aliciene Cordeiro e Mitsuko Antunes (2010), a psicologia pode ser vista como uma forma cultural

portadora de conteúdos que correspondem a representações do fenômeno psicológico, alicerçados em determinadas concepções de homem e de mundo. (CORDEIR0; ANTUNES, 2010, p. 39) 
Para essa investigação, utilizamos como recorte os textos sobre educação moral e educação estética publicados entre 1879 e 1881 . Neles aparece, de forma mais evidente, o tema da formação do ser humano, bem como os conceitos de natureza humana e de faculdades da alma subjacentes às discussões sobre educação.

\section{A moderna pedagogia e o desenvolvimento das forças animais racionais e morais do ser humano}

Em O Baependyano, Siqueira afirma que a moderna pedagogia ${ }^{9}$ trata a educação como sendo

o alargamento, a expansão, o desenvolvimento das forças animaes racionais e moraes no homem; e que o adorna a instrucção, que vem a ser a obtenção das noções, e a qual é um acessório indispensável e necessário da educação. ${ }^{10}$

Para definir educação dessa forma, Siqueira apropria-se do conceito apresentado no manual pedagógico intitulado Curso teórico e prático de pedagogia (1885) ${ }^{11}$, citado frequentemente pelo redator da Secção Scientífica ou Pedagógica.

Tal manual, escrito pelo educador francês Michel Charbonneau ${ }^{12}$, foi amplamente divulgado em sua época, pois era visto como portador de dupla qualidade: teórica, ao expor os princípios da educação e, assim, elevar o espírito dos professores, fazendo-os pensar; e prática, ao disponibilizar os princípios a todos, com a habilidade própria de um educador fundamentado na experiência (RAPET, 1885).

9 - Vale ressaltar que, para Miguel de Siqueira, as expressões evangelho social, educação das crianças ou moderna pedagogia são sinônimas.

10- O Baependyano, n. 125, 28 dez. 1879, p. 1.

11- Publicado pela primeira vez em 1862.

12 - Michel Charbonneau, (1817-1870) dedicou toda sua vida à formação de educadores. Professor de escola normal de 1835 a 1847, tornou-se inspetor e, mais tarde, diretor. Dirigiu escolas normais de diversas regiões da França. Foi convidado para a direção das escolas de Paris, mas morreu antes de poder assumir o cargo.
Em seu livro, Charbonneau (1885) afirma que a alma é formada por três faculdades: inteligência, ou seja, a faculdade de conhecer; sensibilidade, faculdade de gozar ou sofrer; e a vontade, faculdade responsável pela livre escolha. Embora constituída por três aspectos, a alma, de acordo com ele, seria única, sendo as faculdades entendidas como forças que funcionariam em uníssono. A sensibilidade e a vontade, reunidas, formariam o domínio moral. Ao receber a vida, o ser humano receberia essas forças em potência, ou seja, seus germens. Assim, as faculdades fariam parte da natureza humana, pois seriam dadas por Deus como características intrínsecas da alma humana.

A fim de direcionar e contribuir para o pleno desenvolvimento dessas faculdades, a educação dividir-se-ia em dois tipos: a espontânea e a regular. A primeira teria como objeto o desenvolvimento espontâneo das forças da criança na prática cotidiana e sob a influência do meio em que a criança vive, sem a intervenção calculada de professores e pais. Entretanto, o pedagogo francês afirma ser a educação regular o tema central de seu livro. Assim, o manual francês trata da educação regular, ou seja, das relações entre a instrução (como instrumento da educação) e o desenvolvimento do homem, principalmente seu aperfeiçoamento moral. Apesar de valorizar a educação espontânea e a instrução, Charbonneau concebe o desenvolvimento moral como ponto primordial da educação.

Assim, no jornal $O$ Baependyano, é sobretudo a fim de formar moral e intelectualmente o homem para o serviço da sociedade e do Estado que Siqueira se apropria das ideias de Charbonneau, afirmando que o grande intuito da educação, segundo a moderna pedagogia,

\footnotetext{
é preparar o homem na criança para a família, para o Estado, para a paz e para a guerra, para toda e qualquer occupação honesta, ou industria útil, avultando entre nós em primeiro plano - a lavoura, o nervo e vigor dos Estados. ${ }^{13}$
}

13- O Baependyano, n. 192, 15 maio 1881, p. 1-2. 
Em seu manual, Charbonneau assegura que a educação tem por finalidade formar o homem na criança, mas não especifica que isso signifique prepará-lo para a lavoura e para o vigor do Estado.

Compartilhando do objetivo dos redatores do jornal de formar o trabalhador nacional e já se inserindo no espírito positivista que marcaria a Primeira República brasileira, Siqueira define a boa educação como aquela que não tem o objetivo de formar sábios teóricos ou metafísicos nebulosos, mas bons cidadãos. 0 homem social seria caracterizado por bons pais e bons trabalhadores capazes de assentar os alicerces da felicidade futura dos filhos, das famílias, das sociedades e dos Estados ${ }^{14}$.

Ao tratar a educação como ciência teórica e prática, responsável pela expansão das forças racionais e morais do homem, e como sendo o preparo do homem na criança, Siqueira expressa ideias bastante antigas no campo da educação e da filosofia. Estabelecendo uma síntese entre ideias de Emílio, de Jean Jacques Rousseau, e de Michel Charbonneau, o autor parte da premissa de que o desenvolvimento das faculdades racionais e morais acontece quando o ser humano passa de um estado primitivo a um estado moral. Entretanto, como é bem próprio da cultura mineira, Siqueira concilia suas concepções filosóficas e educacionais com a doutrina católica, apropriando-se de inúmeras referências ao cristianismo e, inclusive, denominando a educação como evangelho social. Desse modo, como Siqueira bem afirma em O Baependyano, é possível harmonizar o "bom antigo, com o bom moderno"15.

Para Rousseau, o indivíduo passou por um estado natural em que era feliz por poder dar livre expansão à sua natureza sensível; porém, tal condição já se perdeu e só pode ser reconquistada mediante uma renovação coletiva e pessoal das condições originárias de inocência e pureza (ROVIGHI, 2002). Vivendo em sociedade, é inevitável que o ser humano desenvolva-

14 - O Baependyano, n. 91, 6 abr. 1879.

15- O Baependyano, n. 93, 23 abr. 1879, p. 1. -se, modificando e aperfeiçoando a si mesmo e às relações sociais, mas também corrompendo sua natureza e produzindo desigualdade na sociedade (ROVIGHI, 2002). Essa modificação é a construção da moralidade, que só é possivel se o indivíduo passar de um estado primitivo para um estado social.

[...] apenas no estado social, as faculdades da alma se exercitam e se desenvolvem de modo a possibilitar que o ser humano passe de uma condição estúpida e limitada para tornar-se inteligente. (ABBAGNANO; VISALBERGHI, 1992, p. 391)

Desse modo, a educação é responsável pela transição de uma condição primitiva para uma sociável.

[...] nascemos fracos, precisamos de força; nascemos carentes de tudo, precisamos de assistência; nascemos estúpidos, precisamos de juízo. Tudo o que não temos ao nascermos e de que precisamos quando grandes nos é dado pela educação. (ROUSSEAU, 2004, p. 9)

E é principalmente no sentido de afirmar a premente necessidade de uma correta ação pedagógica capaz de promover o autêntico pacto social que José Miguel de Siqueira parece apropriar-se de Emílio. Apontando para a importância de educar o homem na criança, o autor mineiro cita um trecho do livro em que Rousseau discute a relevância de educar as crianças desde a infância:

tenho sempre observado que os moços corrompidos desd'o berço, são intractaveis, deshumanos, cruéis; sua imaginação preoccupada unicamente por um só objecto, furta-se á tudo mais, não conhecem nem piedade, nem misericórdia; sacrificarão pae e mãe, e até, se precizo for, o universo em pezo, ao menor de seus prazeres. Mas, bem pelo contrario, o jovem criado 
e educado em venturoza simplicidade, esse é suavemente atraído pelos primeiros movimentos da natureza para as paixões ternas, brandas e affectuosas; seu compassivo coração condóe-se das afflicções de seus similhantes; pula d'alegria quando torna a ver seu companheiro d'infancia; jubilozo, abraça-o estreitamente, é affavel, chora de ternura. ${ }^{16}$

Ou seja, os homens não são maus por natureza, mas tornam-se maus devido ao desvio de suas forças do bom caminho, ao ensino dos hábitos e à educação ruim. Segundo Rousseau (2004), "nascemos capazes de aprender, mas sem nada saber e nada conhecendo" (p. 46). Assim, o homem é corrompido e desvirtuado de sua própria natureza pelo mau ensino, por maus exemplos e pela inserção em uma sociedade já corrompida.

Todavia, exatamente porque $O$ Baependyano valoriza o fato de o ser humano ter que ser educado na sociedade e para a sociedade, Siqueira tece uma modesta crítica a Rousseau e elege a teoria de Friedrich Froebel ${ }^{17}$ como a mais adequada ao pensamento moderno sobre educação. Segundo o autor da Secção Scientífica ou Pedagógica, enquanto Rousseau faz do ser humano um "insulado, um ermitão, um solitário" ${ }^{18}$, Froebel trata o homem como um ser que não pode ser separado da sociedade, de seu centro natural e de suas condições de vida básica. Nesse sentido, o autor mineiro afiança a possibilidade da corrupção da alma humana pelo convívio com a sociedade, mas parece sugerir que a saída está em cuidar da educação e não em retirar crianças e jovens do natural convívio social.

Em O Baependyano, a pedagogia de Froebel é descrita pela metáfora da linha de um novelo que se vai desenrolando:

16 - O Baependyano, n. 124, 21 dez. 1879, p. 1.

17- Em O Baependyano, José Miguel de Siqueira utiliza a grafia Frobel e não Froebel. Entretanto, no presente artigo, optamos pela grafia Froebel, por ser a mais correta.

18 - O Baependyano, n. 124, 21 dez. 1879, p. 1. funda seu systema de educação no desdobramento e desinvolução das ingênitas e fecundas forças do homem, que se torna ao depois, pelo assim dizer, numa espécie de creador, que haure em seu próprio fundo tudo que em si encerra a maneira da planta, que é o gérmen desdobrado e desenvolvido. ${ }^{19}$

A linha é a representação das faculdades da alma infantil, que se desenvolvem ao longo do tempo, como descreve o autor mineiro: desdobram-se, desfiam-se e dilatam-se. De acordo com Siqueira, a partir de Froebel, a moderna pedagogia é vista como portadora de um novo conceito de educação, definida como ação e desenvolvimento e que evidencia a atividade criadora humana.

De fato, a pedagogia de Froebel, inspirada em Friedrich Schelling, Karl Krause e Johann Pestalozzi, enfoca a boa natureza da alma infantil e a importância da relação concreta que a criança estabelece com o mundo (ARCE, 2002). Diante disso, o pedagogo alemão afirma a necessidade de os métodos educacionais estimularem a tendência da criança à atividade (ABBANGANO; VISALBERGHI, 1992). Como uma necessidade interna, a atividade é algo espontâneo no ser humano e que, se bem cultivada, forma naturalmente o homem.

[...] o menino que joga tranqüilamente, com atividade espontânea, resistindo à fadiga, chegará seguramente a ser um homem também ativo, resistente, capaz de sacrificar-se pelo seu próprio bem e pelos demais. (FROEBEL, 2001, p. 47-48)

Desse modo, em cada etapa da vida, o ser humano deve aspirar somente àquilo que o período exige, respeitando o que é natural de cada idade e preparando, assim, a etapa de desenvolvimento seguinte. Segundo Froebel (2001), "só um desenvolvimento suficiente em cada idade

19 - O Baependyano, n. 124, 21 dez. 1879, p. 1. 
assegura o desenvolvimento pleno na idade seguinte" (p. 38). Desenvolvendo-se plenamente, o ser humano é capaz de expressar sua atividade criadora e, consequentemente, o trabalho.

\section{A educação espontânea, a educação regular e a instrução}

Nos periódicos do século XIX, é comum que a educação e a instrução sejam objeto de inúmeras discussões. Como afirma Mônica Yumi Jinzenji (2010), os termos educação e instrução aparecem constantemente nos textos da época como dois aspectos relacionados entre si, sendo a instrução geralmente entendida como o enriquecimento das faculdades intelectuais e a educação como desenvolvimento das faculdades morais.

Entretanto, assim como não encontramos apenas uma definição de psicologia, também não encontramos apenas um significado para as relações entre instrução e educação. Em O Baependyano, embora educação e instrução apareçam relacionadas, a educação é entendida como desenvolvimento das forças morais, mas também das faculdades intelectuais do ser humano. A instrução, por sua vez, está mais centrada na aquisição de conhecimentos e conteúdos específicos o que, evidentemente tem relação direta com as faculdades intelectuais.

Siqueira, ainda recorrendo a Charbonneau, discorre sobre a educação espontânea e a formal ou regular. Sobre a espontânea, ele assevera:

Os germens e as forças que a infância contem em si, podem na verdade desinvolver-se espontaneamente, sem a intervenção cautelada dos mestres e dos Paes, pela pratica quotidiana, e sob a influencia do centro no qual a criança habitualmente vive. [...] Mas a experiência está todos os dias a mostrar nos, e a razão claramente vê que esta educação é lenta, penoza, incerta, não dá senão resultados mui incompletos, e, as vezes lamentáveis, e que por si só é, enfim, insufficiente e defeituosa e chega até a dizer-se que os que foram assim educados não tem educação. ${ }^{20}$

Uma vez que não se deveria deixar a criança abandonada apenas à educação espontânea, Siqueira afırma ser indispensável adotar um método educacional capaz de auxiliar no desenvolvimento natural do corpo e da alma, de modo a favorecê-lo, guiá-lo e completá-lo. Sua discussão revela uma concepção de educação que tem por finalidade desenvolver as faculdades humanas e dirigi-las por meio dos ensinamentos da moralidade.

Nessa perspectiva, a educação é entendida como dividida em duas partes distintas: uma delas é a cultura, ou seja, o desenvolvimento e o direcionamento das faculdades da alma humana; a outra é a instrução ou a aquisição de conhecimentos, a qual, por sua vez, também auxilia no desenvolvimento dos aspectos racionais do ser humano.

Consequentemente, há duas partes á distinguir na educação; propriamente dicta, isto é, a cultura, o desinvolvimento e direcção dos germens e faculdades do homem; e a instrucção isto é, a aquizição de conhecimentos. ${ }^{21}$

Assim, apesar de a cultura ser a parte da educação responsável pelo direcionamento da totalidade das faculdades da alma, a instrução permite o desenvolvimento da razão. Porém, "a instrucção não se confunde com a educação" ${ }^{2}$, mas é ela um instrumento indispensável para que a educação alcance seu objetivo final, de desenvolver e aperfeiçoar o ser humano. Sendo assim, a instrução "é a luz da cabeça"23, e seu valor está no auxílio que presta à educação, desenvolvendo a razão de acordo com os ensinamentos morais. Seu principal instrumento é a leitura.

20- 0 Baependyano, n. 125, 28 dez. 1879, p. 1.

21- Ibid

22 - Ibid.

23 - 0 Baependyano, n. 122, 7 dez. 1879, p. 1. 
Para o desenvolvimento da razão reta e sólida, capaz de encaminhar o ser humano para o caminho do bem, o ensino deve ser aprazível, amorável e também capaz de polir não só a inteligência, mas também os hábitos. De acordo com Siqueira, o homem a ser formado pela educação reta e sólida deve ser devedor a Deus, ao próximo e à pátria. Sendo um simples cidadão, deve trabalhar com o suor de seu rosto e utilizar seu talento de forma a ser útil para a sociedade.

Nesse sentido, a instrução, quando desenvolve adequadamente a razão, contribui para habituar a alma a ser dócil e a ouvir nossa voz interna denominada consciência. Siqueira retoma aqui o antigo tema das relações entre razão e sensibilidade, ou seja, a formação da razão esclarecida unida ao sentimento moral e religioso levaria a alma a domar os desejos mundanos e a repreender as paixões nocivas ao ser humano. Assim, a razão não é entendida apenas como raciocínio lógico, mas como instrumento indispensável para a escolha do bem.

Vive o homem quase sempre em paiz enimigo, vivendo consigo mesmo. 0 sangue que ferve em caixões, a imaginação que desvaira, os desejos que se combatem, as paixões que se inflammam, formam uma guerra intestina que vem a ter, muitas vezes, as mais funestas conseqüências. A vida se passa em luctar cada um consigo mesmo, quando quer reger-se com sizudeza, porque, há em nós dois homens, o homem terrestre, e o homem espiritual ou celeste, - que andam de continuo em contenda, e nunca concordam entre si, enquanto a razão convenientemente illustrada, e o coração recto não lhes serve, pelo dizer assim, de leme e de piloto. ${ }^{24}$

A partir da tópica agostiniana que aponta para a luta entre o homem terrestre e o homem celeste, Siqueira considera a consciência como a "luz do mundo moral, e juiz inexorável de nos-

24 - O Baependyano, n. 125, 28 dez. 1879, p. 1. sas acções, que as vezes chamamos-a de voz do Bom Anjo" ${ }^{25}$; daí a necessidade de os educandos serem instruídos por um ensino reto e sólido.

Assim, instrução e cultura seriam aspectos indissociáveis, pois a eficácia da educação dependeria de sua capacidade de cultivar a alma nos aspectos cognitivos e morais, desenvolvendo as faculdades da alma humana para a escolha racional do caminho do bem. Esse direcionamento das faculdades seria necessário, já que a virtude, ao lado da razão, é considerada a força que se opõe à violência das paixões e dos desejos ilícitos, ajudando-nos a vencermos a nós mesmos para praticarmos o bem. Entretanto, o caminho que envolve a escolha do bem na vida adulta deveria iniciar-se na infância, já que, na ausência de um guia para o seu desenvolvimento, a criança pode corromper-se facilmente.

Podemos encontrar, na Seç̧ão Scientífica ou Pedagógica, trechos em que a alma infantil é apresentada como uma tábula rasa na qual a educação é responsável por imprimir as virtudes e os bons hábitos. Apesar de utilizar Froebel como uma de suas referências, ao tratar da natureza humana, Siqueira parece optar pela concepção de que o ser humano possui maus instintos inscritos em si, sendo possível que as forças da alma sejam desviadas do bom caminho pelos maus hábitos. Esse aspecto, de acordo com o autor mineiro, pode ser demonstrado pela experiência, segundo a qual se observa que a alma possui também instintos maus capazes de levar as faculdades a inclinarem-se para a destruição de si e da sociedade.

[...] é todavia certo, que há também, em gérmen nas crianças, uns certos instictos maus, umas certas propensões nascentes, que cumpre, em primeiro lugar as mães, preceptoras natas, e depois os mestres, corrigir desde de cedo, guiando-as para o bem, para que de futuro venham á ser pessoas honradas, honestas, boas, virtuozas. Tudo está nos princípios da educação. ${ }^{26}$

25 - O Baependyano, n. 121, 30 nov. 1879, p. 1.

26- O Baependyano, n. 124, 21 dez. 1879, p. 1. 
Nesse sentido, haveria uma sempre presente luta da alma humana entre a ordenação propícia à sua natureza, que a levaria para o bem, e os maus instintos auxiliados pelos hábitos ruins. Toda essa dinâmica estaria em gérmen na criança e, assim, seria possível pressentir paixões e instintos capazes de revelar um mau caráter. 0 problema aconteceria, portanto, quando aos instintos e às más inclinações de uma criança junta-se uma educação mal dirigida. Como a educação, para o ser humano, é responsável pela passagem de uma primeira natureza primitiva para uma segunda natureza civilizada, diante de tais instintos, é necessário que os mestres e os pais eduquem de forma ativa logo na infância. Nessa época, corrige-se com mais facilidade o que é natural e defeituoso, tal como nas plantas, quando seu caule é ainda tenro. Assim, a educação deve ser entendida como um remédio a ser aplicado no início da doença, pois um hábito, depois de construído, torna-se mecânico, sendo muito difícil modificá-lo.

A ideia de que o hábito, uma vez formado, é de difícil mudança é muito antiga no campo da filosofia e da educação; podemos remontá-la a Aristóteles, que, na obra Ética a Nicômaco, trata amplamente da busca do justo meio para a adequada formação do hábito virtuoso capaz de direcionar o ser humano rumo à felicidade e à excelência. Em $O$ Baependyano, a formação do hábito e a ideia do justo meio tomam outros sentidos e são retiradas da pedagogia de Froebel.

Difficil coisa é sem duvida doutrinar a mocidade seguindo um justo meio termo entre o mínimo rigor e a frouxidão, temperando a severidade com a brandura! [...] A coacção da mente, longe d'iluminar, ao contrario, torna rombo o juízo, bronco o entendimento, e bolonio o educando. ${ }^{27}$

27- O Baependyano, n. 88, 16 mar. 1879, p. 1.
Froebel, em A educação do homem, apresenta a concepção de que a educação deve observar e seguir a natureza espontânea da criança, evitando a coação, as prescrições e a direção excessiva. Desse modo, cumpriria ao bom educador e ao bom discípulo procurar o terceiro termo em suas ações, ou seja, "a eleição do justo e do melhor, que pode necessária e logicamente deduzir-se das condições dadas" (FROEBEL, 2001, p. 29). Torna-se fundamental, então, o cultivo das virtudes nos corações infantis, pois os educadores, os pais ou as amas "salvam ou perdem o homem na infância" 28 . Miguel de Siqueira compara a criança a um livro em branco:

um livro em branco, cujas as folhas limpas esperam, que nellas se escreva, conceberemos quam essencial seja, que mão mestra, mão firme e segura, mão prudente e sabia estampe, esse livro vivo em characteres indeléveis, a virtude; quanto deve a mãe, o pae, o mestre ou mestra cuidar em estabelecer sua auctoridade na educação para que essa auctoridade benéfica obre no infantil espírito do alumno ou alumna como um principio salutar, natural e sagrado. ${ }^{29}$

Em referência ao conceito de tábula rasa, a educação recebida na tenra idade é aí concebida como reguladora de nossa vida inteira, pois as primeiras impressões, os primeiros traços, seriam os fatores formativos do caráter e da conduta dos sujeitos em sociedade.

Segundo essa concepção, desde seu nascimento, o homem vive constantemente dentro de si um combate contra as paixões, o qual se torna mais forte durante a mocidade. Enquanto a boa educação não assume o papel de cultivar e direcionar as faculdades da alma, o conflito passional vivido pela alma humana não cessa. Nesse jogo entre o bem, o mal e o desenvolvimento das faculdades da alma, Miguel de Siqueira recorre à educação estética como meio

28 - O Baependyano, n. 121, 30 nov. 1879, p. 1

29- Ibid. 
privilegiado para conhecer a verdade. De acordo com a educação do belo, o conhecimento da verdade faz-se possível por meio do desenvolvimento da faculdade imaginativa. Isso se dá porque o belo é um fenômeno da imaginação e a verdade expressa-se por meio dele.

Para a instrução e a aquisição do conhecimento, seria necessário dar aos homens, além de ideias puras, imagens sensiveis que os tocassem e os levassem a perceber a verdade. Assim, a educação estética é tão essencial na formação dos alunos quanto a educação intelectual e moral; porém, no desenvolvimento dessa faculdade, bem como no de todas as outras, verificamos a importância da boa educação e da formação dos preceptores para que os educandos consigam atingir o objetivo final da educação.

\section{Conclusão}

No periódico mineiro analisado, a educação é defınida como a unidade entre cultura e instrução. A cultura é concebida como a principal responsável pelo direcionamento das faculdades da alma e pela formação moral, mas a instrução também desempenha um papel importante na formação dos hábitos e dos costumes. Assim, a proposta educativa que circula em $O$ Baependyano não possui nada de muito diferente das ideias educacionais de sua época, as quais veem a pedagogia como o conjunto de saberes e práticas responsáveis pela formação do ser humano em suas dimensões física, intelectual, moral, social e espiritual.

A concepção de que a instrução não deve reduzir-se a formar apenas a inteligência, mas também auxiliar na conduta moral e no desenvolvimento de virtudes e bons hábitos, pode ser encontrada também em outros impressos. Em 1846, o jornal Selecta Catholica, publicado pela Diocese de Mariana, Minas Gerais, afirma que polir a inteligência não era suficiente para garantir a felicidade da pessoa e a saúde da sociedade, pois nem sempre uma grande capacidade intelectual encontra-se aliada às virtudes. Nesse sentido, a conduta virtuosa não é consequência necessária de uma inteligência brilhante (ASSIS, 2005) e, por isso, o pleno desenvolvimento das faculdades intelectuais e morais deve acontecer em uníssono.

Um pleno desenvolvimento indica o direcionamento das faculdades da alma para a virtude e o bem. A educação, portanto, tem a finalidade de encaminhar as nascentes inclinações para o bem, a fim de reprimir as paixões e os desejos ilícitos. No caso de $O$ Baependyano, o caminho da virtude e do bem coincide com o ideal de homem social, ou seja, aquele caracterizado pela polidez, pela disposição para o trabalho capaz de construir a sociedade e pela utilidade a si, ao próximo e ao Estado. Desse modo, o periódico insere-se no projeto de civilizar, instruir e educar seus leitores, tendo como aspecto central de seu discurso a preparação do homem para o trabalho em um contexto em que as leis escravocratas sofrem profundas mudanças.

A pedagogia, como bem reflete as páginas de $O$ Baependyano, é vista como meio soberano de promover uma sociedade mais equilibrada e harmoniosa, propiciando, assim, a construção da pátria. Ela é entendida como o instrumento por meio do qual os homens passam do estado natural ao estado social, desenvolvendo e enriquecendo sua alma mediante a aquisição de conhecimento e a formação dos princípios da moralidade. Nessa perspectiva, Siqueira enfatiza a educação infantil devido à sua importância para a formação do homem social.

Os jornais que se intitulavam políticos, noticiosos, científicos e literários são permeados por uma organização original e expressiva das visões de mundo dos grupos que os publicavam. De acordo com Maria Marta Araújo (2008), pode-se afirmar que, no século XIX, o periódico foi o principal laboratório da invenção literária no Brasil, tal como já vinha ocorrendo na Europa. Da mesma forma que na literatura, os saberes científicos e filosóficos também vão encontrar sua expressão na cultura impressa do 
período, que buscava divulgar diversos saberes de forma mais popularizada.

Os saberes de presença mais marcante nos escritos morais e estéticos da Secção Scientífica ou Pedagógica são provenientes de Emílio, de Jean-Jacques Rousseau, e do manual Curso teórico e prático de pedagogia, escrito por Michel Charbonneau, havendo também referência à pedagogia de Friedrich Froebel e às ideias católicas. É curioso notar, entretanto, que encontramos citações e trechos traduzidos dos livros de Rousseau e de Charbonneau, mas não há referências diretas às obras de Froebel que nos permitam identificar de que maneira Siqueira leu o autor. Assim, apesar de eleger Froebel como o autor mais adequado para a pedagogia moderna, as maiores apropriações de Siqueira são das obras de Rousseau e de Charbonneau, o que fica evidente na discussão sobre a natureza humana e a possibilidade de sua corrupção quando diante de uma educação mal dirigida.

0 autor mineiro apropria-se de diversas ideias, mas desenvolve um discurso próprio sobre a educação e sua relação com a natureza humana. Esse discurso afırma a necessidade de uma educação cujo objetivo é o direcionamento das faculdades inerentes à alma, a fim de que o ser humano desenvolva-se plenamente e de forma a contribuir para a construção de uma sociedade pautada pelo trabalho. Nesse sentido, a cultura é instrumento fundamental de adequação da natureza humana aos objetivos de uma sociedade que, inevitavelmente, deve estruturar-se como pátria.

Ao recorrer a autores como Froebel e Charbonneau, Siqueira parece buscar a inserção em um discurso sobre a educação capaz de diferenciar os fundamentos da pedagogia moderna daqueles da pedagogia antiga. De acordo com Joaquim Pintassilgo (2010), a dicotomia entre pedagogia antiga e pedagogia moderna

é uma das marcas distintivas do discurso pedagógico do período de transição entre $o$ século XIX e o século XX e que lhe serve de ponto de ancoragem e de união. (p. 14)

Uma das características da pedagogia considerada moderna é o valor atribuído à observação da natureza infantil. Nessa observação e investigação da natureza da criança, a fım de subsidiar a prática pedagógica, os saberes sobre as faculdades da alma adquirem um lugar de destaque. 


\section{Referências}

ABBAGNANO, Nicola; VISALBERGHI, Aldo. Historia de la pedagogía. Mexico, D. F.: Fondo de Cultura Económica, 1992.

ARAÚJO, Maria Marta. Uma história de precursores e ativistas. Revista do Arquivo Público Mineiro, Belo Horizonte, n. 1, p. 2023, jun. 2008.

ARCE, Alessandra. Friedrich Froebel: o pedagogo dos jardins da infância. Petrópolis: Vozes, 2002.

ASSIS, Raquel Martins de. A importância da educação e da tradição: lições do jornal religioso Selecta Catholica (1846 - 1847) sobre 0 cultivo das faculdades da alma e do espírito humano. Memorandum, Belo Horizonte, v. 8, p. 106-115, 2005.

Psicologia filosófica no século XIX: faculdades da alma e relações entre inteligência, sensibilidade e vontade. Psicologia: Reflexão e Crítica, Porto Alegre, v. 22, p. 304-311, 2009.

ASSIS, Raquel Martins de et al. História da psicologia da educação em Minas Gerais: relações entre saberes psicológicos em educação em jornais mineiros do século XIX. In: LOURENÇO, Érika; GUEDES, Maria do Carmo; CAMPOS, Regina Helena de Freitas (Orgs.). Patrimônio cultural, museus, psicologia e educação: diálogos. Belo Horizonte: Editora PUCMinas, 2009. p. 185-206.

ASSIS, Raquel Martins de; SILVA, Flávio de Ligório. Psicologia filosófica em compêndios do século XIX: contribuições para a história da psicologia da educação em Minas Gerais. Relatório de pesquisa. Faculdade de Educação, Universidade Federal de Minas Gerais, Belo Horizonte, 2006. 44 p.

ASSIS, Raquel Martins de; SILVA, Paulo José de Carvalho; PACHECO, Paulo R. Andrade. Seminários Católicos do Brasil Colônia e Império. In: JACÓ-VILELA, Ana Maria. Dicionário histórico de instituições de psicologia no Brasil. Rio de Janeiro: Imago; Brasília: Conselho Federal de Psicologia, 2011. p. 385-387.

BAHIA, Juarez. Jornal, história e técnica. São Paulo: Ibrasa, 1972.

CAMISASCA, Marina; VENANCIO, Renato. Jornais mineiros do século XIX: um projeto de digitalização. Cadernos de História, ano II, n. 1, mar. 2007. Disponível em: <http:// www.ichs.ufop.br/cadernosdehistoria/download/CadernosDeHistoria-03-15-Dossie. pdf>. Acesso em: 27 ago. 2007.

CASTILHO, Fábio Francisco de Almeida. Entre a locomotiva e o fiel da balança: transição da mão-de-obra no Sul de Minas (1870-1918). Dissertação (Mestrado) - Universidade Federal de Juiz de Fora, Juiz de Fora, 2009.

CERTEAU, Michel de. A invenção do cotidiano: artes de fazer. Petrópolis: Vozes, 1994.

CHARBONNEAU, Michel. Cours théorique et pratique de pédagogie. Paris: Librairie Ch. Delagrave, 1885.

CORDEIRO, Aliciene F. Machado; ANTUNES, Mitsuko A. Makino. A ação pedagógica de Itard na educação de Victor, o "selvagem de Aveyron": contribuição à história da psicologia. Memorandum, Belo Horizonte, v. 18, p. 37-49, 2010. Disponível em: <http:// www.fafich.ufmg.br/ memorandum/a18/cordeiroantunes01.pdf>. Acesso em: 19 out. 2010.

COSTA FILHO, Miguel. A imprensa mineira no Primeiro Reinado: independência_política, imperador constitucional e integridade do império. Tese apresentada ao VI Congresso Nacional de Jornalistas. Rio de Janeiro, 1955.

FARIA FILHO, Luciano Mendes de et al. Educar para civilizar. Revista do Arquivo Público Mineiro, v. XLIV, p. 72-87, 2008.

FROEBEL, Friedrich. A educação do homem. Tradução de Maria Helena Câmara Bastos. Passo Fundo: Editora UPF, 2001.

JINZENJI, Mônica Yumi. Cultura impressa e educação da mulher no século XIX. Belo Horizonte: Editora UFMG, 2010.

LUSTOSA, Isabel. 0 nascimento da imprensa brasileira. Rio de Janeiro: Jorge Zahar Editor, 2003. 
MASSIMI, Marina. A psicologia em instituições de ensino brasileiras do século XIX. Tese (Doutorado em Psicologia) Universidade de São Paulo, São Paulo, 1989

NEPOMUCENO, Denise Maria; CAMPOS, Regina Helena de Freitas. Fontes para a difusão das idéias psicológicas em Minas Gerais entre 1830 e 1930. Memorandum, Belo Horizonte, v. 6, p. 114-123, 2004. Disponível em: <http://www.fafich.ufmg. br/ memorandum/artigos06/nepcampos01.htm>. Acesso em: 15 jan. 2012.

NEVES, Lúcia Maria Bastos P. Antídotos contra obras "ímpias e sodiciosas": censura e repressão no Brasil de 1808 a 1824. In: ABREU, Márcia (Org.). Leitura, história e história da leitura. Campinas: Mercado das Letras; Associação de Leitura do Brasil; São Paulo: Fapesp, 1999. p. 377-394.

NEVES, Lúcia Maria Bastos P.; MOREL, Marco; FERREIRA, Tânia Maria Bessone da C. (Orgs.). História e imprensa: representações culturais e práticas de poder. Rio de Janeiro: DP\&A, 2006.

OLIVEIRA, José Carlos. A cultura científica e a Gazeta do Rio de Janeiro. Revista da Sociedade Brasileira de História da Ciência, n. 17, p. 29-58, 1997

PALLARES-BURKE, Maria Lúcia. Nísia Floresta, o Carapuceiro e outros ensaios de tradução cultural. São Paulo: Hucitec, 1996.

PELUCIO, José Alberto. Baependi. São Paulo: Ed. do Autor, 1942.

PINTASSILGO, Joaquim. Os manuais de pedagogia no primeiro terço do século XX: entre a tradição e a inovação. 2006. Disponível em: <http://repositorio.ul.pt/bitstream/10451/4020/1/0s\%20manuais\%20de\%20Pedagogia.pdf>. Acesso em: 15 jan. 2012.

RAPET, Jean-Jacques. Introduction: utilité et but dês études pédagogiques. In: CHARBONNEAU, Michel. Cours théorique et pratique de pádagogie. Paris: Librairie Ch. Delagrave, 1885.

RODRIGUES, José R. da Costa. Idéias filosóficas e políticas em Minas Gerais no século XIX. Belo Horizonte: Itatiaia; São Paulo: EDUSP, 1986.

ROUSSEAU, Jean-Jacques. Emílio ou Da educação. Tradução de Roberto Leal Ferreira. São Paulo: Martins Fontes, 2004.

ROVIGHI, Sofia Vanni. História da filosofia moderna: da revolução cientifica a Hegel. São Paulo: Ed. Loyola, 2002.

SANTOS, João Antônio dos. 0 esqueleto das faculdades e a origem das idéias do espírito humano, obra mui útil para os moços que se applicão ao estudo de Philosophia. Mariana, MG: Tipografia Episcopal de Mariana, 1847.

SCHWARCZ, Lilia Moritz. As barbas do imperador: D. Pedro Il, um monarca nos trópicos. São Paulo: Companhia das Letras, 1998.

Recebido em: 11.11.2010

Aprovado em: 22.09.2011

Raquel Martins de Assis é professora do Programa de Pós-Graduação em Educação: Conhecimento e Inclusão Social, da Universidade Federal de Minas Gerais. Atua em docência e pesquisa nas áreas de História da Psicologia da Educação e Psicologia da Educação.

Juliana de Souza Martins é graduada em Pedagogia pela Universidade Federal de Minas Gerais e participou, como bolsista de iniciação científica, de pesquisas em História da Psicologia da Educação no Brasil. E-mail: julianaszm@yahoo.com.br. 
